\title{
Intercomparison of Aircraft and Surface Buoy Meteorological Data during CODE-1 ${ }^{1}$
}

\author{
CARL A. FrIEHE ${ }^{2}$ \\ Department of Mechanical Engineering, University of California, Irvine, CA 92717 \\ ROBERT C. BEARDSLEY \\ Woods Hole Oceanographic Institution, ${ }^{3}$ Woods Hole, MA 02543 \\ Clinton D. Winant \\ Scripps Institution of Oceanography, La Jolla, CA 92093 \\ JEROME P. DEAN \\ Woods Hole Oceanographic Institution, Woods Hole, MA 02543
}

(Manuscript received 29 August 1983, in final form 16 January 1984)

\begin{abstract}
Intercomparisons of meteorological data - wind speed and direction, surface temperature and surface pressurewere obtained for NCAR Queen Air overflights of four buoys during the CODE-1 experiment. The overflights were at a nominal altitude of $33 \mathrm{~m}$. Wind and air temperature sensors were at $10 \mathrm{~m}$ on two National Data Buoy Office (NDBO) buoys and at $3.5 \mathrm{~m}$ on two Woods Hole Oceanographic Institution (WHOI) buoys. The buoy wind speeds were adjusted to the aircraft altitude using diabatic flux-profile relations and bulk aerodynamic formulas to estimate the surface fluxes and stability. For the experimental period (22 April-23 May 1981) and location (northern coast of California), the atmospheric surface layer was generally stable, with the MoninObukhov length on average $500 \mathrm{~m}$ with large variability.

The results of the intercomparisons of the above variables were in general good. Average differences (aircraft - buoy) and standard deviations were $+0.1 \mathrm{~m} \mathrm{~s}^{-1}( \pm 1.8)$ for wind speed, $3.3 \mathrm{deg}( \pm 11.2)$ for wind direction, $+0.02^{\circ} \mathrm{C}( \pm 1.7)$ for air temperature and $+0.8 \mathrm{mb}(+1.0)$ for surface pressure. The aircraft downward-looking infrared radiometer indicated a surface temperature $1^{\circ} \mathrm{C}$ lower than the buoy hull (NDBO) and $1 \mathrm{~m}$ immersion (WHOI) sea temperature sensors.
\end{abstract}

\section{Introduction}

The Coastal Ocean Dynamics Experiment (CODE) was designed to study the wind-driven ocean circulation over the northern California shelf between Point Reyes and Point Arena. As part of CODE-1, the first intensive small scale experiment (see Allen et al., 1982, for a preliminary description of the overall CODE-1 field program), the temporal and spatial structure of the atmospheric boundary layer was examined using two complementary observational techniques: long-term monitoring at a few specific points with moored meteorological buoys, and high resolution spatial mapping with an instrumented research aircraft, operated by the National Center for Atmospheric Research (NCAR). The purpose of this report is to present in-

\footnotetext{
' Coastal Ocean Dynamics Experiment.

${ }^{2}$ Former affiliation: The National Center for Atmospheric Research (NCAR), Boulder, Colorado.

${ }^{3}$ Woods Hole Oceanographic Contribution No. 5451 and CODE Contribution No. 3.
}

tercomparisons of the meteorological data from NCAR aircraft overflights made at a nominal altitude of 33 m (100 feet) over the NOAA Data Buoy Office (NDBO) environmental buoys 46013 and 46014 and meteorological buoys $\mathrm{C} 3$ and $\mathrm{C} 5$ developed by the Woods Hole Oceanographic Institution (WHOI). The locations of the buoys are shown in Fig. 1, and the list of variables measured is given in Table 1. Intercomparisons such as these are needed to determine the performance of the different observational systems and sensors in order to lend confidence to the use of data from both systems for future data analysis and experiments.

Stuart et al. (1980) have presented comparisons of wind speed from similar NCAR aircraft overflights at $152 \mathrm{~m}$ to buoy winds from sensors at 2.4 and $3 \mathrm{~m}$ above the sea surface. As can be expected, the aircraft winds were significantly higher than the buoy wind speeds due to the wind shear in the boundary layer. They presented a correlation of the data, but made no attempt to account for the wind shear between the winds at the different heights. Intercomparisons between NCAR aircraft and tower measurements over 


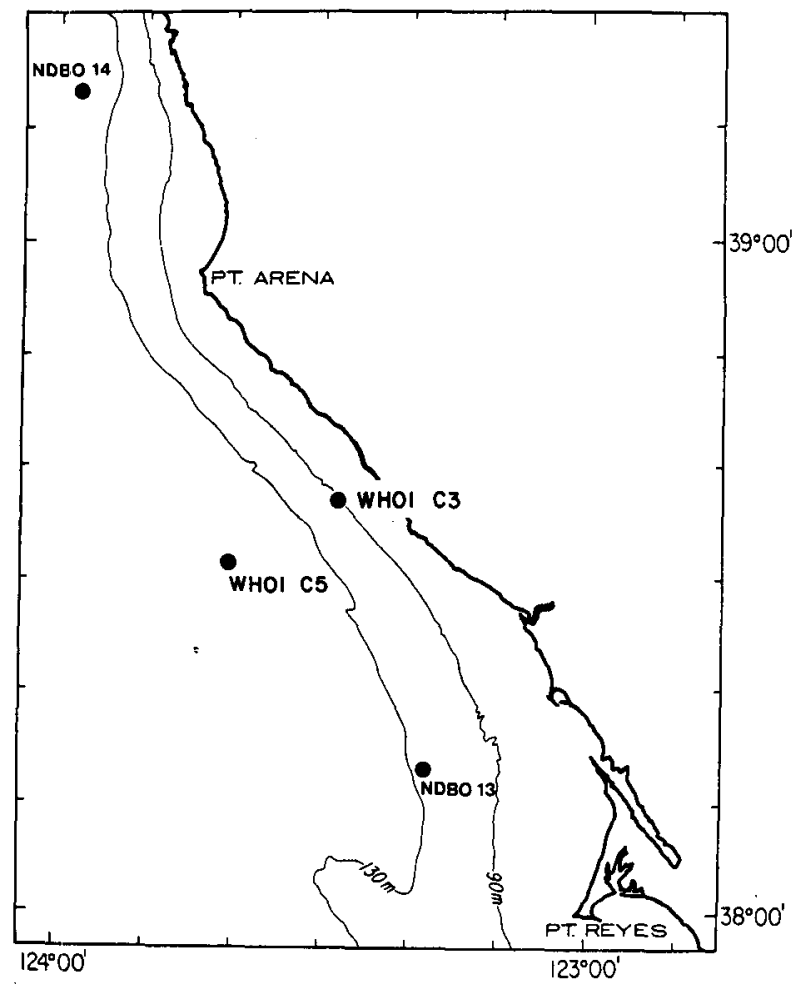

FIG. 1. Simplified topographic map of the Northern California shelf showing locations of the two NDBO buoys 13 (46013) and 14 (46014) and the two WHOI buoys C3 and C5.

land by Lenschow and Stankov (1980), for example, have yielded good results. These were at higher levels, where the aircraft flew at the same level as the sensors on the tower (BAO $300 \mathrm{~m}$ tower, Boulder, CO). Wind speeds at 150 and $300 \mathrm{~m}$ agreed to within $\sim 1 \mathrm{~m} \mathrm{~s}^{-1}$ and air temperature to within $\sim 0.6^{\circ} \mathrm{C}$. Variances of wind components and temperature also agreed well.

Nicholls (1982) obtained comparisons between aircraft (WK C130) and research ship data project JASIN. Wind speed, wind direction, surface pressure and air temperature data agreed within nominal system measurement accuracies. Sea surface temperatures from the aircraft radiometer were $\sim 0.5^{\circ} \mathrm{C}$ less than the ship bucket temperatures.

For the present experiment, the wind and air temperature sensors were mounted at $10 \mathrm{~m}$ and $3.5 \mathrm{~m}$

TABLE 1. Buoy locations and measurements.

\begin{tabular}{|c|c|c|}
\hline Buoy & Location & $\begin{array}{l}\text { Sensors and heights } \\
\quad(z)\end{array}$ \\
\hline NDBO 13 & $38^{\circ} 12^{\prime} \mathrm{N}, 123^{\circ} 18^{\prime} \mathrm{W}$ & $\begin{array}{l}\text { Wind speed, direction }(10 \mathrm{~m}) \\
\text { Air temperature }(10 \mathrm{~m})\end{array}$ \\
\hline NDBO 14 & $39^{\circ} 13^{\prime} \mathrm{N}, 123^{\circ} 57^{\prime} \mathrm{W}$ & $\begin{array}{l}\text { Barometric pressure }(0 \mathrm{~m}) \\
\text { Sea temperature }(-0.3 \mathrm{~m} \text {, in hull })\end{array}$ \\
\hline WHOI C3 & $38^{\circ} 36.5^{\prime} \mathrm{N}, 123^{\circ} 28.1^{\prime} \mathrm{W}$ & $\begin{array}{l}\text { Wind speed, direction }(3.5 \mathrm{~m}) \\
\text { Air temperature }(3.5 \mathrm{~m})\end{array}$ \\
\hline WHOI C5 & $38^{\circ} 31.2^{\prime} \mathrm{N}, 123^{\circ} 40.5^{\prime} \mathrm{W}$ & Sea temperature $(-1.0 \mathrm{~m})$ \\
\hline
\end{tabular}

elevation on the NDBO and WHOI buoys, respectively, and therefore extrapolations are required to adjust the aircraft variables down to 10 and $3.5 \mathrm{~m}$ or the buoy variables up to $33 \mathrm{~m}$. In this study, we chose to use the surface layer flux-profile relations of Businger $e t$ $a l$. (1971) to adjust the buoy wind and temperature data up to the aircraft levels. For surface pressure intercomparison, aircraft static pressure was extrapolated to the sea surface with the assumption of a standard atmosphere. Sea surface temperature is measured with an infrared radiometer on the aircraft.

\section{Buoy and aircraft sensors}

NOAA Data Buoy Office environmental buoys 46013 (NDBO-13) and 46014 (NDBO-14) are $10 \mathrm{~m}$
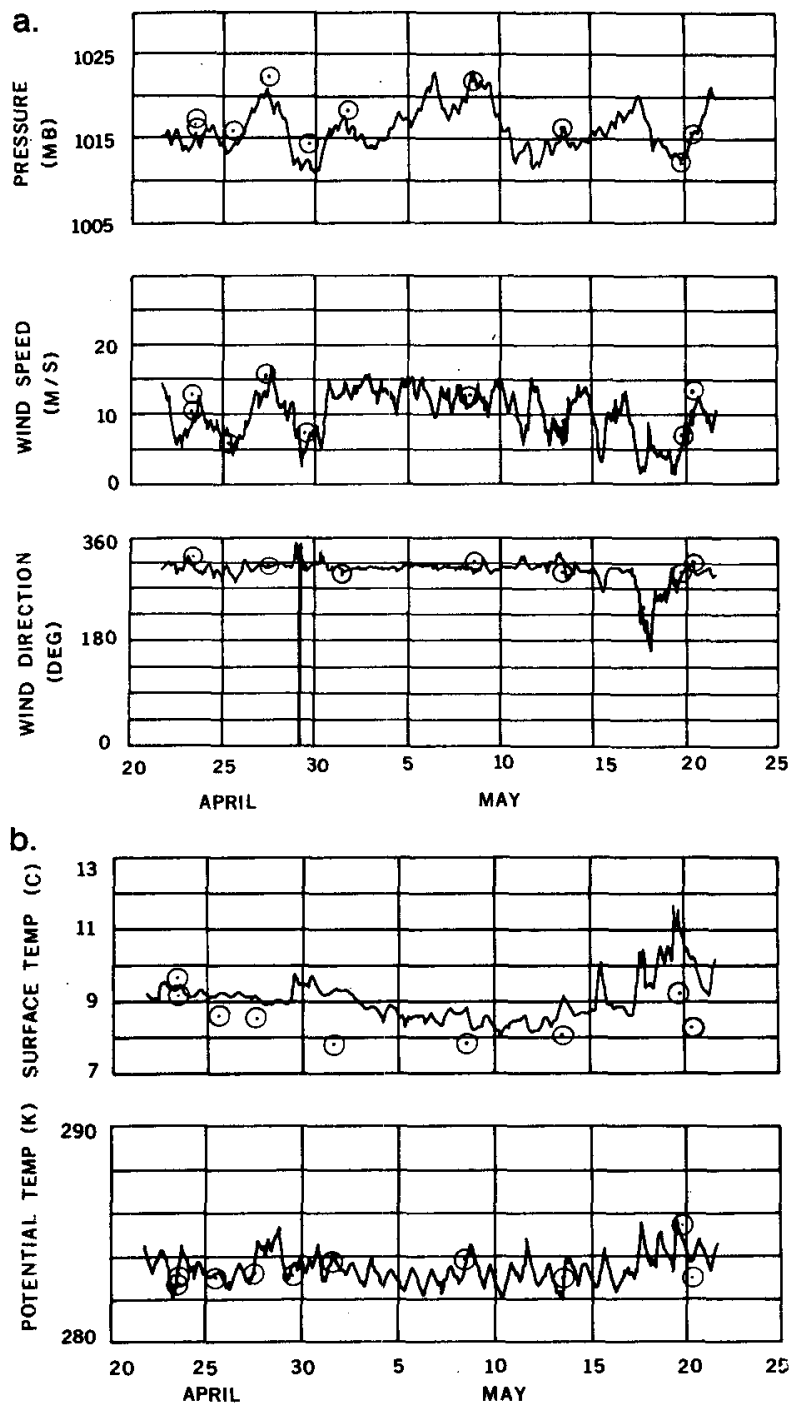

FIG. 2. Time series of meteorological data from NDBO 46013 for the period 22 April-22 May 1981: (a) Surface pressure (mb), wind speed $\left(\mathrm{m} \mathrm{s}^{-1}\right.$ at $10 \mathrm{~m}$ ) and wind direction (deg from true north at $10 \mathrm{~m})$; (b) Radiometric surface temperature $\left({ }^{\circ} \mathrm{C}\right)$, potential air temperature $(\mathrm{K}), \odot 33 \mathrm{~m}$ aircraft data. 

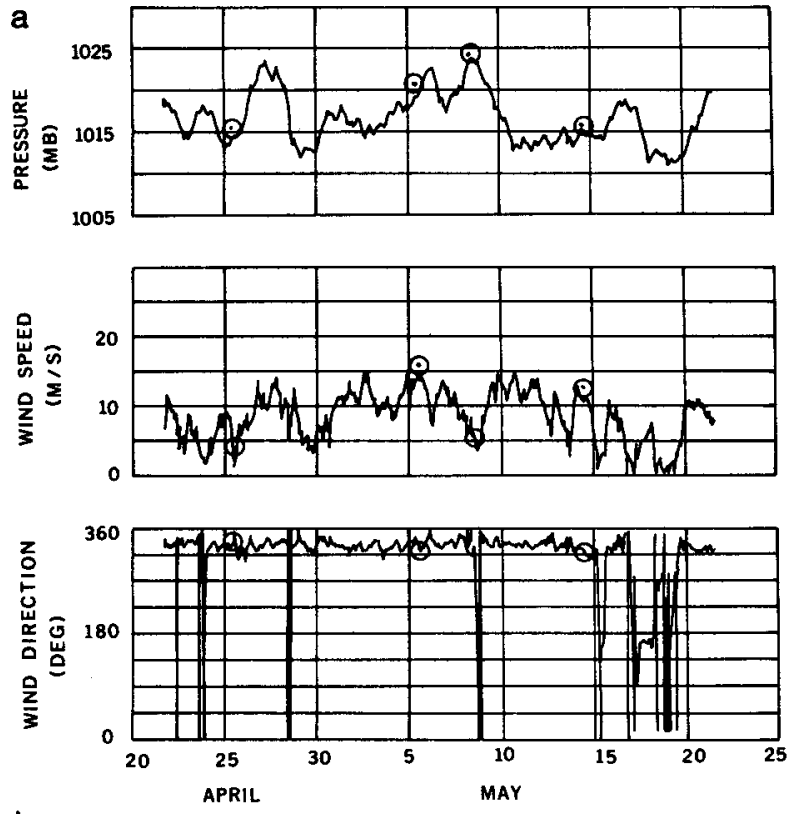

b
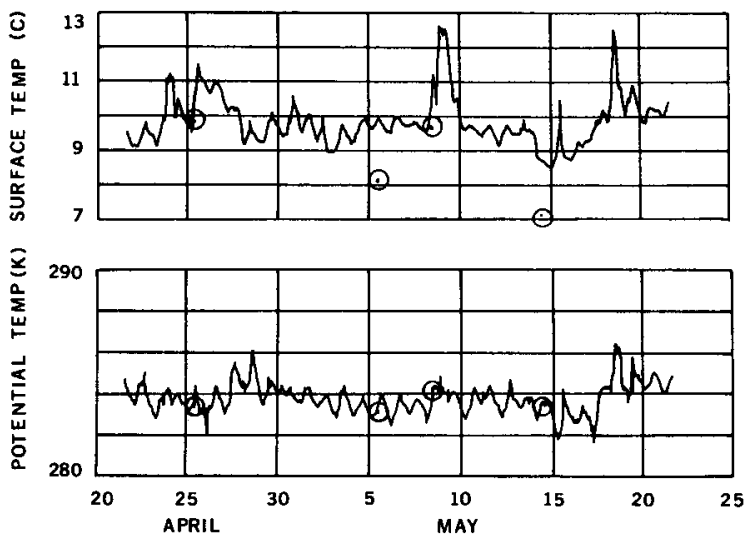

FIG. 3. As in Fig. 2 except for NDBO 46014.

diameter slack-moored discus buoys. These buoys are instrumented with standard NDBO instruments and programmed to transmit data hourly via satellite. A Bendix-Friez Model 120 propeller-vane anemometer or a J-Tec vortex shedding sensor is used at $10 \mathrm{~m}$ height to measure wind speed. For CODE-1, the Bendix-Friez was used for the wind data (R. Erichsen, personal communication, 1983). Wind direction is obtained by a tilt-compensated (to $30^{\circ}$ ) fluxgate compass attached to the vane axis. Wind speed and direction data are sampled each second for $8.5 \mathrm{~min}(512 \mathrm{~s})$ before the hour and for $58 \mathrm{~min}$, and both averages are of the orthogonal components transmitted each hour. Wind difference measurements are adjusted for the magnetic variation at each mooring site to give wind direction data relative to true North. Wind speed accuracy is $\pm 1 \mathrm{~m} \mathrm{~s}^{-1}$ above a threshold of $1 \mathrm{~m} \mathrm{~s}^{-1}$ and is within $10 \%$ from 10 to $50 \mathrm{~m} \mathrm{~s}^{-1}$. The wind direction data are accurate to about $\pm 4^{\circ}$, and the anemometer has a distance constant of about $5 \mathrm{~m}$.
Air temperature is sensed at the $10 \mathrm{~m}$ height with a YS1 thermistor mounted in a radiation shield, with an accuracy estimated at $\pm 1.0^{\circ} \mathrm{C}$. Water temperature is estimated indirectly with a similar thermistor mounted on the inside of the buoy hull below the water line. The air and sea temperature sensors are sampled once each hour at the end of the $512 \mathrm{~s}$ acquisition period.

Atmospheric pressure is measured with a capacitive diaphragm-type pressure transducer (Rosemount, Inc.). The system accuracy is $\pm 1.0 \mathrm{mb}$. Pressure is sampled every four seconds during the $512 \mathrm{~s}$ period. The average value of these 128 samples is transmitted as the hourly pressure record. (See Hamilton, 1980, for a more detailed description of the NDBO buoy sensor systems.)

The Woods Hole Oceanographic Institution toroid buoys at locations $\mathrm{C} 3$ and $\mathrm{C} 5$ were instrumented with modified vector-averaging current meters designed to function as wind recorders (VAWR, vector-averaging wind recorder). The wind-vane and three-cup anemometers are patterned after designs by G. Gill (R.M. Young Co.) and modified to provide the necessary digital inputs to a vector computer module. The wind sensors are mounted $3.5 \mathrm{~m}$ above the water line. The anemometer threshold is less than $0.5 \mathrm{~m} \mathrm{~s}^{-1}$, and the distance constant is $3.7 \mathrm{~m}$. The vane has a similar threshold and a damping ratio of 0.37 . Wind speed accuracy is estimated to be better than $\pm 0.2 \mathrm{~m} \mathrm{~s}^{-1}$ or $5 \%$ of reading including buoy motion effects.

For redundancy and comparison of radiation shields, two temperature measurements were made at $3.5 \mathrm{~m}$ elevation. The sensors were thermistors mounted in naturally-ventilated radiation shields, one a Thaller-
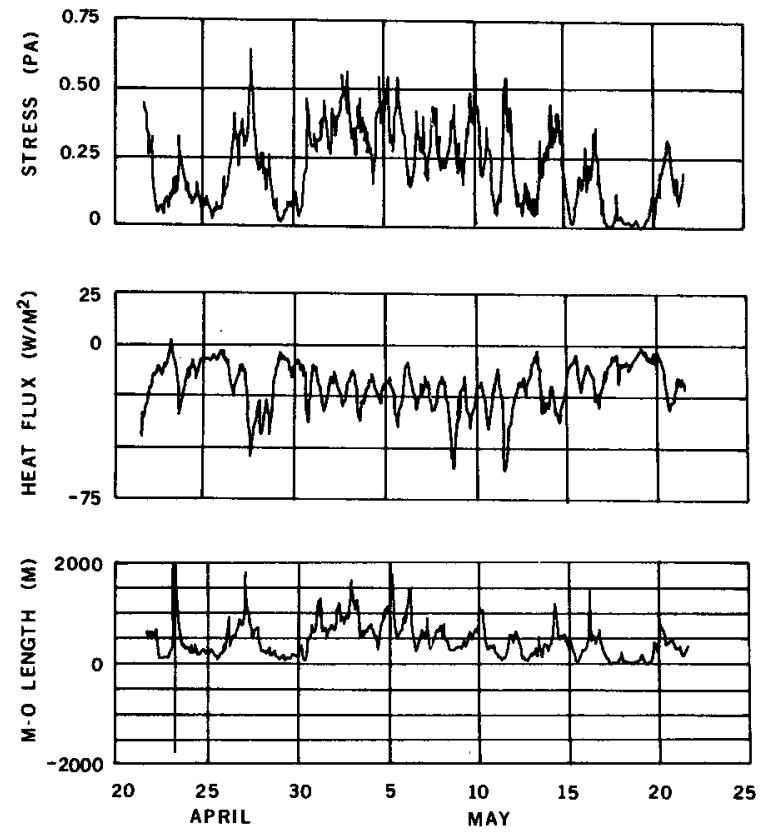

Fig. 4. Time series of calculated surface flux parameters for NDBO 46013: stress (Pa), heat flux ( $\left.\mathrm{W} \mathrm{m}^{-2}\right)$, Monin-Obukhov length (m). 

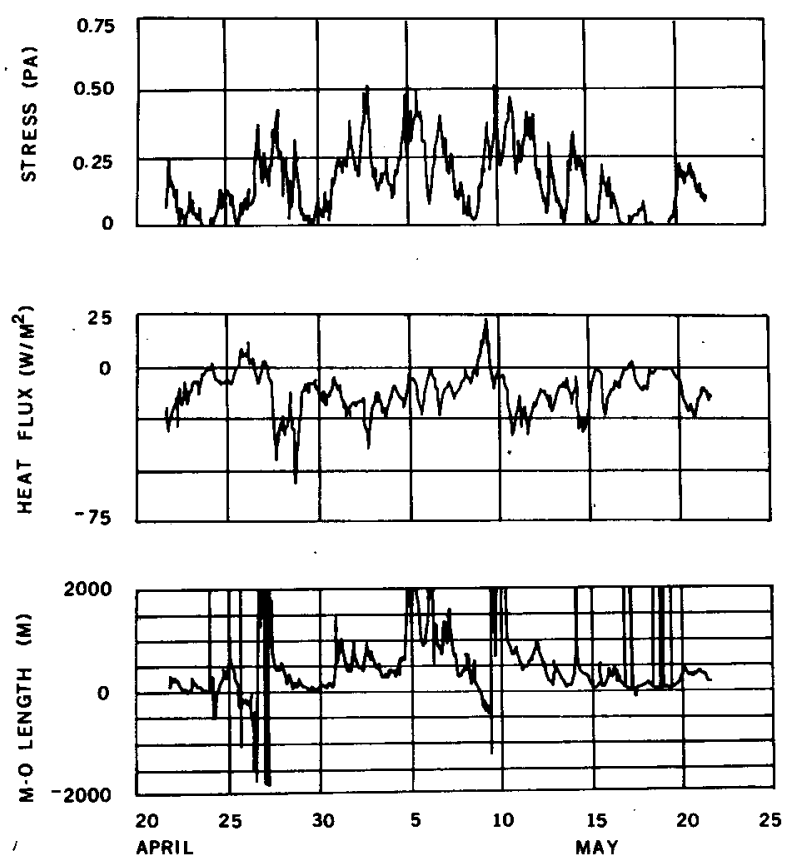

FiG. 5. As in Fig. 4 except for NDBO 46014.

type shield similar to a design by G. Gill, the other a glass-dome type (R.M. Young Co.) modified for use on the buoys at sea. The Thaller shield proved to be more effective by about a factor of 2 and is accurate to $\pm 0.3^{\circ} \mathrm{C}$; the sensor accuracy is $\pm 0.1^{\circ} \mathrm{C}$. Sea temperature was measured at $1 \mathrm{~m}$ depth with a calibrated thermistor sensor in a protected housing. The sea temperature measurement accuracy is $\pm 0.005^{\circ} \mathrm{C}$.

The data are stored and recorded on a Phillips-type data cassette each $450 \mathrm{~s}$ (7.5 $\mathrm{min})$. The wind data are vector-averaged over the full record interval. Temperature data are averaged for about one-fourth of the record interval (110.7 s). Incident solar radiation was also measured and averaged over the record interval, but is not discussed here. A more detailed description of the WHOI VAWR and a preliminary description of the meteorological conditions prevailing during CODE- 1 are given by Mills and Beardsley (1983).

The aircraft was an NCAR Queen Air, equipped with a nose boom-inertial navigation-Pitot tube and vane system for measurement of the total velocity vector relative to an earth-based coordinate system (see Lenschow, 1972, for a description of the system and general principles). Frequent in-flight wind calibration maneuvers, consisting of flying 2 min upwind and 2 min downwind, indicated that the horizontal wind speed measurements were usually better than $0.75 \mathrm{~m}$ $\mathrm{s}^{-1}$. Air temperature was obtained from a standard aircraft probe (Rosemount 102EAL) with corrections made for dynamic heating. Static pressure was obtained from the measured static pressure on the fuselage and a correction equation obtained by flying the aircraft past a precision barometer on the NOAA BAO $300 \mathrm{~m}$ tower at various airspeeds. Static pressure accuracy, after correction, is estimated at $\pm 0.5 \mathrm{mb}( \pm 50 \mathrm{~Pa})$. From the corrected static pressure and the absolute altitude above the ocean surface measured simultaneously with a radar altimeter, the surface pressure was obtained by assuming, a standard atmosphere between the aircraft and the ocean surface.

Sea surface temperature was measured with a infrared thermometer (Barnes PRT-5) operating in the $8-12 \mu$ wavelength band. A viewing window was not required on the unpressurized Queen Air, and corrections were not made for absorption in the air column below the aircraft or non-ideal emissivity of the sea surface. At $33 \mathrm{~m}$ altitude, the PRT-5 has a spot area of $\sim 0.3 \mathrm{~m}^{2}$ on the ocean surface. The absolute accuracy of the PRT-5 is not known, but is probably not better than $\pm 1^{\circ} \mathrm{C}$.

Data are recorded on computer compatible tape on the aircraft at 50 and $5 \mathrm{~Hz}$, depending on the sensor type (Duncan and Brown, 1978), and reduced, calibrated measurements are produced at 20 and $1 \mathrm{~Hz}$. The exact time of over-flight of a buoy was manually noted in the aircraft, and the data were later compared from the reduced and calibrated results from both the
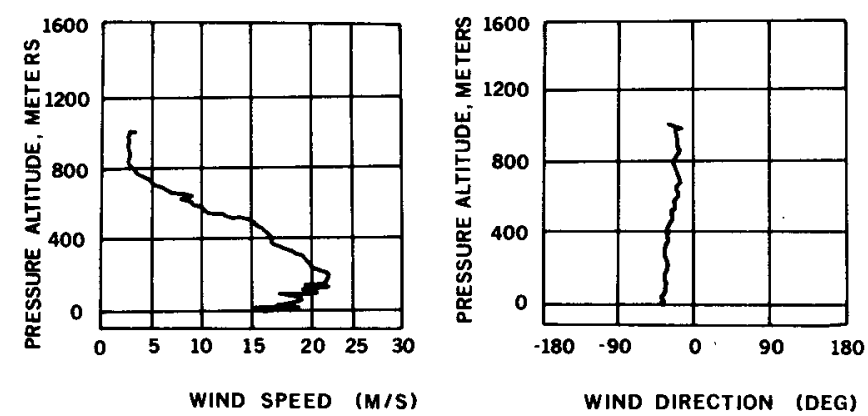

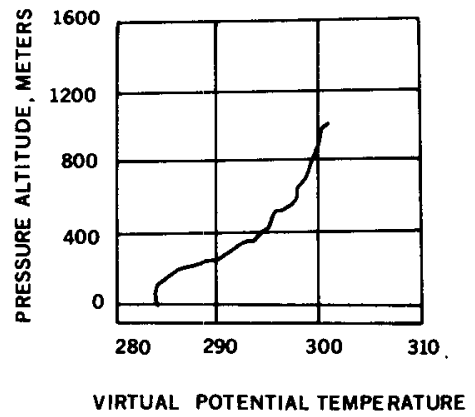

(K)

FIG. 6. Example of vertical atmospheric profile from NCAR aircraft showing strong wind jet,(left panel), constant wind direction in lower boundary layer (center panel), and low-level inversion in potential temperature (right panel) at 1320 PST 23 April $1981 ; 38.5^{\circ} \mathrm{N}, 123.6^{\circ} \mathrm{W}$.) 

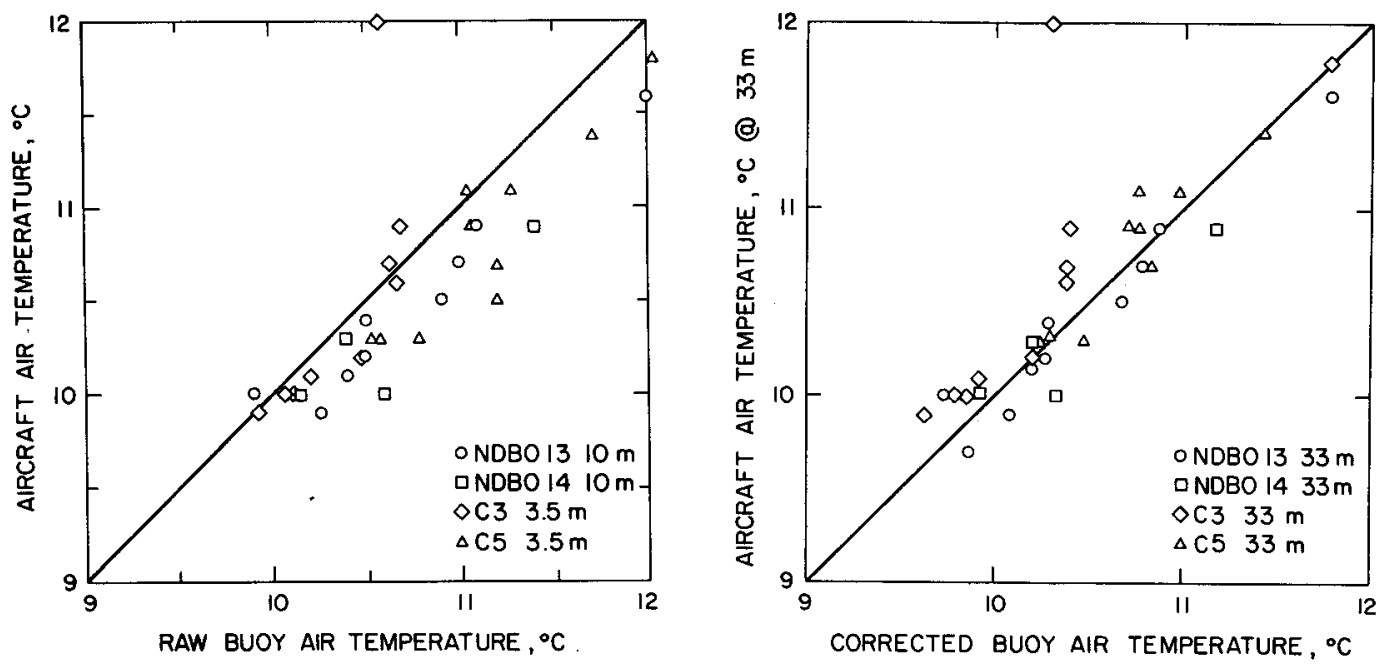

FIG. 7. Comparison of $33 \mathrm{~m}$ aircraft wind speeds and raw NDBO $10 \mathrm{~m}$ and WHOI $3.5 \mathrm{~m}$ wind speeds (left), and corrected NDBO and WHOI $33 \mathrm{~m}$ wind speeds (right). Solid line indicates one-to-one relationship.

aircraft ( $1 \mathrm{~Hz}$ data) and buoys. For the NDBO buoys, the aircraft overflights did not always coincide with the hourly message time, so time differences of up to $30 \mathrm{~min}$ were possible. However, weather conditions in the CODE area were generally steady over $30 \mathrm{~min}$ and the time difference was ignored. For the WHOI buoys, the overflight times were within $7.5 \mathrm{~min}$.

\section{Analysis}

The flux-profile relationships of Businger et al. (1971) were used to calculate wind speed and temperature at different heights in the surface layer where the fluxes of momentum, heat, and moisture are assumed to be independent of height. The thickness of this layer for barotropic conditions is proportional to $u_{*}^{2} / f U_{g}$ where $f$ is the Coriolis parameter, $u_{*}$ the surface friction velocity, and $U_{g}$ is the geostrophic velocity (e.g., see Brutsaert, 1982). For most conditions, this height is of the order of several hundred to a few thousand meters, so that use of the surface layer flux-profiles formulas to compare differences between the near surface buoy data and the $33 \mathrm{~m}$ aircraft data should be valid. For stable buoyancy conditions, the mean wind speed $U$ and potential temperature $\theta$ profiles are given by

$$
\begin{aligned}
& U\left(z_{2}\right)=U\left(z_{1}\right)+\frac{u_{*}}{\kappa}\left[\ln \frac{z_{2}}{z_{1}}+4.7 \frac{\left(z_{2}-z_{1}\right)}{L}\right], \\
& \theta\left(z_{2}\right)=\theta\left(z_{1}\right)+\theta_{*}\left[0.74 \ln \frac{z_{2}}{z_{1}}+4.7 \frac{\left(z_{2}-z_{1}\right)}{L}\right],
\end{aligned}
$$

where $\theta_{*}$ is the friction temperature, $\kappa=0.35, L$ is Monin-Obukhov length $\left(=-u_{*}^{3} T\left(\kappa g w T_{v}\right)^{-1}\right.$, where $T$ is the mean temperature, $g$ the gravitational acceleration, $w T_{v}$ the vertical flux of buoyancy, $T_{v}$ the virtual temperature, $z_{1}$ the buoy sensor height, and $z_{2}$ the aircraft height. ${ }^{4}$

In order to use (1) and (2), $u_{*}$ and $\theta_{*}$ are required. The bulk aerodynamic formulas of Garratt (1977) for $u_{*}$ and Friehe and Schmitt (1976) for $\theta_{*}$ were used without stability corrections to estimate $u_{*}$ and $\theta_{*}$ (and thus $L$ ) from the buoy data. Since humidity data were lacking from the buoys, $L$ for dry air was computed $\left(T_{v}=T\right)$.

For unstable conditions, different flux-profile relations obtained by Businger et al. apply, and the integration scheme of Paulson (1970) was used.

The $58 \mathrm{~min}$ NDBO and $7.5 \mathrm{~min}$ WHOI averaged data were used for the bulk formulas and profile relations.

\section{Buoy results and vertical profile observations}

The overall surface layer conditions during the 22 April-22 May 1981 portion of the CODE-1 field experiment are shown in Figs. 2 and 3, where time series of wind speed and direction, air and sea temperatures, and barometric pressure from the NDBO buoys are presented. The period is characterized by relatively strong and persistent northwest winds (wind from the northwest) with a few synoptic disturbances passing through. The wind direction is roughly parallel to the coast, and the air temperature warmer than the bulk sea temperature. The results of the calculation of surface fluxes and the stability parameter $L$ are shown in Figs. 4 and 5 for the NDBO buoys. The surface stress is reasonably high (reaching $0.75 \mathrm{~Pa}$ ) and buoyancy

\footnotetext{
${ }^{4}$ The stability corrections to the potential temperature data were found to be small, and the data we:e extrapolated using the dry adiabatic lapse rate.
} 


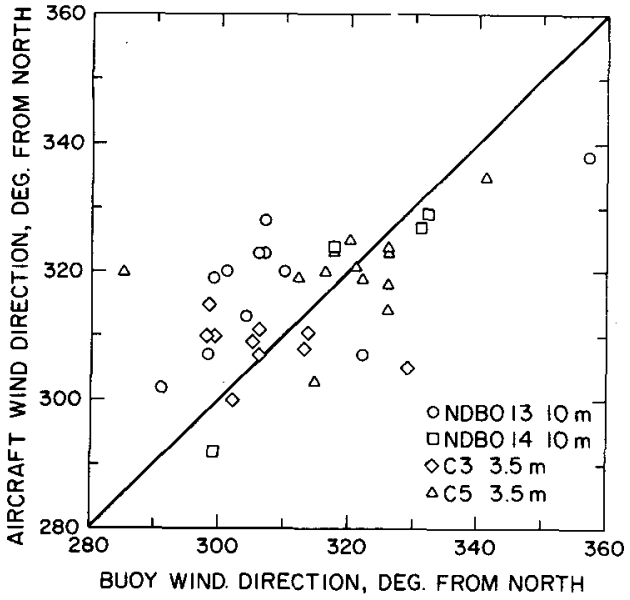

FIG. 8. Comparison of $33 \mathrm{~m}$ aircraft wind direction at NDBO $10 \mathrm{~m}$ and WHOI $3.5 \mathrm{~m}$ wind directions.

conditions are generally stable (negative heat flux from the atmosphere to the ocean). The resulting MoninObukhov length is quite variable but is of the order of $+300 \mathrm{~m}$ at NDBO 46013 and $+500 \mathrm{~m}$ at 46014 .

In the vertical, the typical structure of the marine boundary layer was found to be very stratified from aircraft soundings (Friehe and Winant, 1982), in contrast to the homogeneous assumption made above for estimating the height of the surface layer. Example profiles of wind speed and direction, and potential temperature from the aircraft are shown in Fig. 6 for a typical case at mid-afternoon during the peak of the diurnal cycle. While the vertical structure is very stratified, the overflight height of $\sim 33 \mathrm{~m}$ was always below the low level inversion so that the use of the surface layer formulas is assumed to be valid.

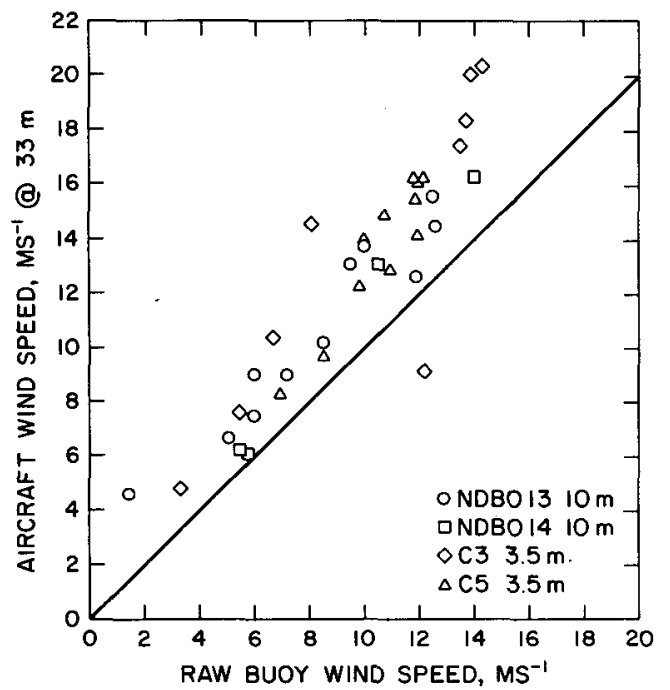

\section{Comparisons of buoy and aircraft data}

The comparisons of the raw 3.5 and $10 \mathrm{~m}$ and extrapolated to the absolute altitude of the aircraft from the radar altimeter) buoy wind speeds and the aircraft wind speeds are shown in Fig. 7. The aircraft winds are higher than the measured buoy wind speeds as expected due to the shear in the surface layer. The correction of the buoy winds brings the two data sets into good agreement: only 3 data points deviate by more than $2 \mathrm{~m} \mathrm{~s}^{-1}$. The wind direction comparison is shown in Fig. 8. The scatter is of the order of 15 $20 \mathrm{deg}$ maximum, assuming no turning of the wind in the surface layer. There is some indication that the wind direction from NDBO 13 may be biased, as most of the values indicate a direction about $20^{\circ}$ less than the aircraft. (Problems with the compass on this particular buoy were occurring during the overflight period (G. Hamilton, personal communication).) Similar results are shown in Fig. 9 for the raw and corrected air temperatures.

The comparison of the barometric (surface) pressure data (NDBO buoys only) is shown in Fig. 10. The maximum deviations are of the order of $\pm 2 \mathrm{mb}$ $( \pm 200 \mathrm{~Pa})$.

Radiometric and buoy bulk sea temperatures are shown in Fig. 11. With few exceptions, the radiometer indicates a lower temperature than the buoy sensors, generally of the order of $1^{\circ} \mathrm{C}$. This corresponds in sign and approximately in magnitude to the results of Paulson and Simpson (1981) from an experiment designed to measure the "cool skin" temperature effects at the ocean surface. However, the heat flux conditions in CODE-1 were different than that of Paulson and Simpson. In CODE-1, the sensible heat flux was usually down and the net radiative flux is expected to be down

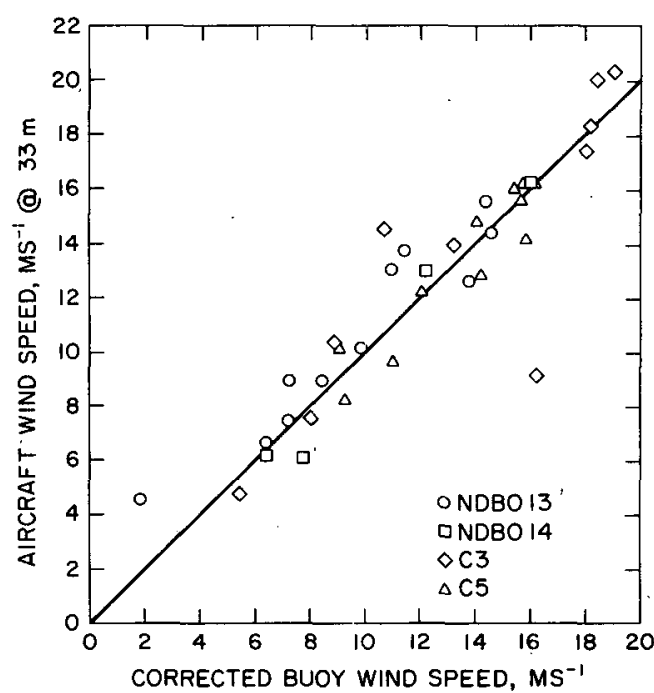

FiG. 9. Comparison of $33 \mathrm{~m}$ aircraft ambient air temperatures and raw NDBO $10 \mathrm{~m}$ and WHOI 3.5 air temperature (left), and corrected NDBO and WHOI $33 \mathrm{~m}$ air temperatures (right). 


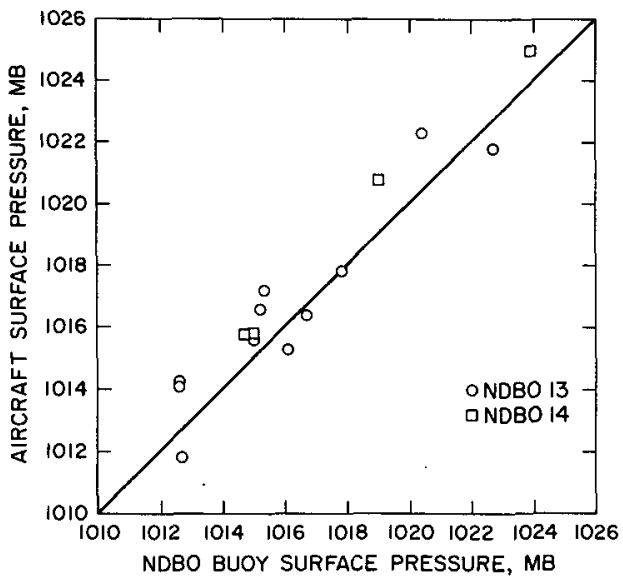

FIG. 10. Comparison of extrapolated surface pressures from the aircraft at $33 \mathrm{~m}$ with NDBO measured surface pressures.

during the daytime overflights, larger than the upward latent heat flux. Thus we would expect a hot skin temperature.

Correlation coefficients and differences between the means of the aircraft and buoy data are shown in Table 2. The differences are negligible and the correlations high for wind speed, air temperature and barometric pressure. The correlations are lower for wind direction and, as noted above, for sea temperature. The correlations of wind speed and direction and air temperature are generally lower for the WHOI data than for the NDBO data. Part of this may be due to the large extrapolation from 3.5 to $33 \mathrm{~m}$, and possible deviations from the flux-profile formulas at $3.5 \mathrm{~m}$ due to the surface waves. Standard deviations of the differences are also given in Table 2.

The error in the inertial navigation system (INS) position was estimated by comparing the final position of the aircraft after the flight at the Sonoma County airport to the initial position entered into the INS at the same place. For the 19 flights, the mean position error was $2.6 \mathrm{~km}(1.4 \mathrm{n} \mathrm{mi})$ with a standard deviation of $0.9 \mathrm{~km}(0.5 \mathrm{n} \mathrm{mi})$. Since the flights averaged approximately $4 \mathrm{~h}$, the average drift rate was inferred to be $\sim 0.65 \mathrm{~km} \mathrm{~h}^{-1}(0.4 \mathrm{kt})$, which is well within the 1 $\mathrm{nm} \mathrm{h}^{-1}$ manufacturer's drift rate tolerance. The value of $0.65 \mathrm{~km} \mathrm{~h}^{-1}$ corresponds to $0.18 \mathrm{~m} \mathrm{~s}^{-1}$, which indicates that inertial navigation drift accounts for only a fraction of the observed $0.75 \mathrm{~m} \mathrm{~s}^{-1}$ wind uncertainty. Dynamic and static pressure errors probably account for the remaining $0.5 \mathrm{~m} \mathrm{~s}^{-1}$ error.

Position fixes were also taken over the buoys during most of the flights. For eleven fixes over NDBO 13, the average deviation from the buoy's estimated position was $2 \mathrm{~km}(1.1 \mathrm{n} \mathrm{mi})$ with a standard deviation of $8.8 \mathrm{~km}(4.8 \mathrm{n} \mathrm{mi})$. For NDBO 14, four fixes gave an average error of $0.30 \mathrm{~km}(0.16 \mathrm{n} \mathrm{mi})$ with a standard deviation of $1.4(0.75)$.

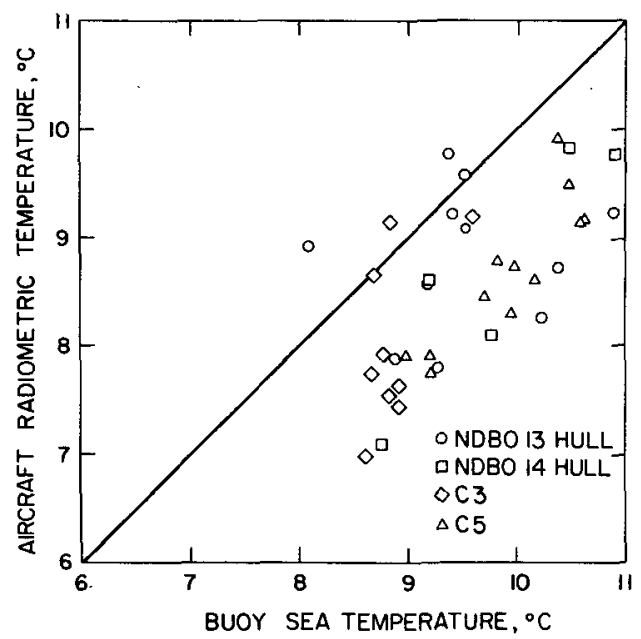

FIG. 11. Comparison of aircraft radiometric $(8-12 \mu)$ surface temperature from aircraft at $33 \mathrm{~m}$ and NDBO and WHOI bulk sea temperatures.

\section{Discussion and conclusions}

The comparisons show good agreement between the aircraft data and the NDBO and WHOI buoy data. The adjustment of the buoy wind speeds and air temperatures to the aircraft height (nominally $33 \mathrm{~m}$ ) by the Businger et al. (1971) flux-profile formulas resulted in substantially improved agreement. The error introduced by the assumption of a constant stress layer between the surface and the low aircraft altitude cannot be readily assessed. From the majority of the aircraft data for CODE-1, the wind speed appears to be almost linear with height below the inversion, whereas the

TABLE 2. Aircraft and buoy comparisons: correlation coefficients.

\begin{tabular}{|c|c|c|c|c|c|}
\hline Variable & $\begin{array}{c}\text { NDBO } \\
46013\end{array}$ & $\begin{array}{l}\text { NDBO } \\
46014\end{array}$ & $\begin{array}{l}\text { WHOI } \\
\text { C3 }\end{array}$ & $\underset{\text { C5 }}{\text { WHOI }}$ & All $†$ \\
\hline $\begin{array}{l}\text { Wind speed } \\
\left(\mathrm{m} \mathrm{s}^{-1}\right)\end{array}$ & 0.92 & 0.98 & 0.86 & 0.93 & $\begin{array}{c}0.91 \\
\mathrm{D}=+0.11 \\
\mathrm{SD}=1.84\end{array}$ \\
\hline $\begin{array}{l}\text { Wind } \\
\text { direction } \\
\text { (deg) }\end{array}$ & 0.86 & 0.99 & -0.35 & 0.64 & $\begin{aligned} & 0.65 \\
D & =+3.3 \\
S D & =11.2\end{aligned}$ \\
\hline $\begin{array}{l}\text { Air tem- } \\
\text { perature } \\
\left({ }^{\circ} \mathrm{C}\right)\end{array}$ & 0.98 & 0.82 & 0.73 & 0.89 & $\begin{aligned} & 0.80 \\
D & =+0.02 \\
S D & =1.74\end{aligned}$ \\
\hline $\begin{array}{l}\text { Sea tem- } \\
\text { perature } \\
\left({ }^{\circ} \mathrm{C}\right)\end{array}$ & 0.29 & 0.97 & 0.49 & 0.88 & $\begin{aligned} & 0.68 \\
D & =-1.0 \\
S D & =0.62\end{aligned}$ \\
\hline $\begin{array}{l}\text { Barometric } \\
\text { pressure } \\
\text { (mb) }\end{array}$ & 0.94 & 0.99 & - & - & $\begin{array}{c}0.96 \\
D=+0.8 \\
S D=1.04\end{array}$ \\
\hline $\begin{array}{l}\text { (Number } \\
\text { of com- } \\
\text { parisons) }\end{array}$ & (10) & (4) & $(10)$ & (11) & $\begin{array}{l}\text { (35, except for } \\
\text { pressure, 14) }\end{array}$ \\
\hline
\end{tabular}

$\dagger D$, difference between means of aircraft and buoy variable. SD, standard deviation between aircraft and buoy variable. 
surface layer formulas give a stability-modified semilogarithmic profile. If we take the stress to be zero at the inversion, the stress divergences are large for most of the intercomparisons, as the inversions were usually low (100 to $500 \mathrm{~m}$ ), and the surface stress high. With a linear decrease of stress with height, a surface stress of $0.5 \mathrm{~Pa}$ and an inversion height of $150 \mathrm{~m}$, the actual stress is reduced to $80 \%$ of the surface value at an altitude of $33 \mathrm{~m}$. This variation may not be large enough to affect the use of the flux-profile relationships.

Acknowledgments. We would like to thank Mike Daniels of NCAR and Carol Mills of WHOI who processed much of the buoy data presented here. George Halliwell of Oregon State University kindly provided the formatted NDBO data tapes. The surface pressure calculation for the aircraft data was done by Keith Griffith of NCAR.

We would also like to thank Gilbert Summers of NCAR, pilot of the Queen Air for his skillful flying during the CODE-1 program, and the personnel from WHOI and NDBO who deployed the buoys.

The National Center for Atmospheric Research is sponsored by the National Science Foundation. The Division of Ocean Sciences, National Science Foundation, supported the field and analysis work at the Woods Hole Oceanographic Institution and Scripps Institute of Oceanography through Grants OCE 8014941 (to RCB and JED) and OCE 80-14942 (CDW), respectively.

The final preparation of this report was completed with NSF support through Grant OCE 82-14949 to $\mathrm{CAF}$ at the University of California, Irvine.

\section{REFERENCES}

Allen, J. S., R. C. Beardsley, W. S. Brown, D. A. Cacchione, R. E. Davis, D. E. Drake, C. Friehe, W. D. Grant, A. Huyer, J. D. Irish, M. M. Janopaul, A. J. Williams and C. D. Winant, 1982: A preliminary description of the CODE-1 field program. Woods
Hole Oceanographic Institution, Tech. Rep. WHOI-82-51, CODE Tech. Rep. 9, Woods Hole, MA.

Brutsaert, W. H., 1982: Evaporation Into The Atmosphere. Riedel, $299 \cdot \mathrm{pp}$.

Businger, J. A., J. C. Wyngaard, Y. Izumi and E. F. Bradley, 1971: Flux-profile relationships in the atmospheric surface layer. $J$. Atmos. Sci., 28, 191-199.

Duncan, T. M., and R. C. Brown, 1978: A data acquisition system for airborne meteorological research. Bull. Amer. Meteor. Soc., 59, 1128-1134.

Friehe, C. A., and K. F. Schmitt, 1976: Parameterization of air-sea interface fluxes of sensible heat and moisture by the bulk aerodynamic formulas. J. Phys. Oceanogr., 6, 801-809.

- and C. D. Winant, 1982: Observations of wind and sea surface temperature structure off of the northern California Coast. First Int. Conf. on Meteorology and Air-Sea Interaction of the Coastal Zone, H. Tennekes and C. N. K. Mooers, Eds., Amer. Meteor. Soc., 209-214.

Garratt, J. R., 1977: Review of drag coefficients over oceans and continents. Mon. Wea. Rev., 105, 915-927.

Hamilton, G. D., 1980: NOAA Data Buoy Office Programs. Bull. Am. Meteor. Soc., 61, 1012-1017.

Lenschow, D. H., 1972: The measurement of air velocity and temperature using the NCAR Buffalo Aircraft Measuring System. NCAR-TN/Edd-74. NCAR, Boulder, CO., 39 pp.

- and B. B. S. Stankov, 1980: Comparison of Aircraft and BAO Tower Measurements. Instruments and Observing Methods Report No. 3, J. C. Kaimal et al., Eds., WMO, Geneva, 26-32.

Nicholls, S., 1982. An observational study of the mid-latitude, marine, atmospheric boundary layer. Ph.D. thesis, University of Southhampton, $307 \mathrm{pp}$.

Paulson, C. A., 1970: The mathematical representation of wind speed and temperature profiles in the unstable atmospheric surface layer. J. Appl. Meteor., 9, 857-861.

- - , and J. J. Simpson, 1981: The temperature difference across the cool skin of the ocean. J. Geophys. Res., 86, 11044-11054.

Mills, C. A., and R. C. Beardsley, 1983: CODE-1: Coastal and Moored Meteorological Observations. CODE-1 Moored Array and LargeScale Data Report, L. K. Rosenfeld, Ed., Woods Hole Oceanographic Institution, Tech. Rep., No. 83-23, CODE Tech. Rep. 21, Woods Hole, MA, $186 \mathrm{pp}$.

Stuart, D. W., R. J. Goodwin and N. P. Duval, 1981: A comparison of surface winds and winds measured at $152 \mathrm{~m}$ during JOINT I, 1974, and JOINT II, 1977. Coastal Upwelling. F. A. Richards, Ed., Amer. Geophys. Union, 39-43. 